\title{
Os desafios das diretrizes curriculares nacionais para a área de educação física: uma análise do período de 1939 a 2015 ${ }^{1}{ }^{2}$
}

\author{
The challenges presented in the national curriculum \\ guidelines for physical education area: an analysis of \\ the period 1939 to 2015
}

\section{Los desafíos de las directrices curriculares nacionales para el área de educación física: un análisis del período de 1939 a 2015}

\author{
(iD) Andreia Cristina Metzner \\ Centro Universitário UNIFAFIBE, Bebedouro, São Paulo, Brasil. \\ E-mail: acmetzner@hotmail.com \\ (iD) Alexandre Janotta Drigo \\ Programa de Pós-graduação em Ciências da Motricidade da Universidade Estadual Paulista \\ "Júlio de Mesquita Filho" - UNESP/Campus de Rio Claro, Rio Claro, São Paulo, Brasil. \\ E-mail: alexandredrigo@hotmail.com
}

\begin{abstract}
Resumo: $O$ artigo teve por objetivo identificar os desafios apresentados na configuração dos textos das Diretrizes Curriculares Nacionais publicadas no período de 1939 a 2015 que orientam a formação em Educação Física e a formação dos professores que atuam na Educação Básica, bem como os pontos de vistas dentro dos grupos políticos relacionados à Educação Física brasileira. Este estudo é de cunho descritivo-analítico. A amostra foi composta por 20 profissionais de Educação Física. Os resultados mostraram que a perspectiva geral dos participantes dos grupos B, C e D indica que houve avanços ao longo da história. Já os participantes do grupo A afirmaram que
\end{abstract}

\footnotetext{
1 Este estudo faz parte da tese de doutorado de Andreia Cristina Metzner, intitulada "Legislação sobre a formação em Educação Física no Brasil: formando professores ou profissionais?", defendida, em outubro de 2019, pelo Programa de Pós-Graduação em Ciências da Motricidade da UNESP/Rio Claro.

2 Apoio da Coordenação de Aperfeiçoamento de Pessoal de Nível Superior - Brasil (CAPES) - Código de Financiamento 001.
} 
as mudanças na legislação não apresentaram resultados positivos ou que não há pesquisas significativas sobre o tema para permitir tal suposição.

Palavras-chave: Educação Física. Legislação. Diretrizes Curriculares Nacionais.

Abstract: The purpose of the article was to investigate the challenges presented in the configuration of the texts of the National Curriculum Guidelines published in the period 1939 to 2015 that regulate the physical education courses and teacher education courses who work in Basic Education, even as the points of view within the political groups related to Brazilian Physical Education. This is a descriptive-analytic study. Participants comprised 20 Physical Education professionals. According to the general perspectives of the participants of groups $B, C$ and $D$, the findings indicate that there were advances as the guidelines. The participants of group $A$ stated that changes in legislation did not provide positive outcomes, or that there is no significant research on the topic to allow such assumption.

Keywords: Physical Education. Legislation. National Curriculum Guidelines.

Resumen: El artículo tuvo como objetivo identificar los desafíos presentadosem La configuración de lostextos delãs Directrices Curriculares Nacionales publicado en el período 1939 a 2015 que guían la formación en Educación Física y la formación de profesores de educación básica, así como los puntos de vista dentro de los grupos políticos relacionados com la Educación Física brasileña. Este es um estúdio descriptivo-analítico. La muestra de estúdio consistió en 20 profesionales de Educación Física. Los resultados mostraron que la perspectiva general de los participantes em los grupos B, C y D indica que ha habido avances a lo largo de la historia. Los participantes del Grupo A, por otro lado, declararon que los câmbios em la legislación no arrojaron resultados positivos o que no hay una investigación significativa sobre el tema que permita tal suposición.

Palabras clave: Educación Física. Legislación. Directrices Curriculares Nacionales.

Submetido em: 13-12-2020

Aceito em: 23-08-2021 
Os desafios das diretrizes curriculares nacionais para a área de educação física: uma análise... Andreia Cristina Metzner • Alexandre Janotta Drigo

\section{Introdução}

As Diretrizes Curriculares Nacionais (DCN) têm como objetivo normatizar os cursos de Ensino Superior, assim, são constituídas por orientações para a elaboração do currículo, com o intuito de construir o perfil acadêmico e profissional desejado a partir das competências, habilidades e conteúdos necessários para assegurar a qualidade da formação inicial e continuada dos docentes para atuar na Educação Básica.

A trajetória histórica das DCN mostra que estas sofreram diversas modificações ao longo dos anos. No caso da Educação Física, as modificações trazidas pelas Diretrizes proporcionaram novas configurações e maneiras de se pensar a formação dos professores/profissionais dessa área.

As primeiras iniciativas de formação de professores nesse campo estiveram atreladas às escolas militares. Somente na década de 1930 foram criadas, no meio civil, escolas para a formação de profissionais de Educação Física, dentre elas citamos a Escola Nacional de Educação Física, da Universidade do Brasil, localizada no Rio de Janeiro (BORGES, 1998). Convém lembrar que a Educação Física em seu início não tinha a pretensão de ser uma disciplina com currículo de conhecimento específico, mas sim uma atividade atrelada à melhoria da aptidão física da população - escolar - brasileira. Nessa realidade, a Educação Física apresentava-se longe de um discurso politizado e organizado, distanciando-se inclusive da identidade docente.

O início do caminho da formação do licenciado em Educação Física, direcionado à docência, era realizado em cursos de apenas dois anos de duração. Posteriormente, por meio da Resolução CFE n. ${ }^{\circ} 69 / 69$, a grade curricular foi reformulada, aumentando a carga horária dos cursos para três anos de duração e determinando um currículo mínimo que contemplasse as seguintes matérias pedagógicas: Didática, Psicologia da Educação, Estrutura e Funcionamento do Ensino, e Prática de Ensino. Essa fase permitiu 
Os desafios das diretrizes curriculares nacionais para a área de educação física: uma análise... Andreia Cristina Metzner • Alexandre Janotta Drigo

que iniciasse uma estrutura mais formal tanto curricular como de curso superior para obtenção do título de licenciado, consequentemente, uma possível identidade docente passou a ser construída.

Em 1987, a Resolução n. 03 (Res. CFE n. ${ }^{\circ}$ 03/1987) reconhece o curso de bacharelado e aponta a possibilidade da formação em Educação Física a partir de dois campos de trabalho: o ensino formal e o ensino não formal. Nessa "nova habilitação", o curso de licenciatura não foi estruturado de maneira a atender às necessidades de reconhecimento do ambiente escolar, conforme expresso nas DCN posteriores. Como consequência, os cursos ofereciam as duas habilitações (bacharelado e licenciatura) em uma única formação.

Na década de 90, ocorreram reformas educacionais em vários níveis de ensino, dentre eles o Ensino Superior. No que concerne aos cursos de licenciatura, o início dos anos 2000, por meio das DCN n. 01 e n. 02 de 2002, foi determinante na reformulação e modificação dos currículos de formação inicial de professores (Res. CNE/CP n. ${ }^{\circ}$ 01/2002; Res. CNE/CP n. ${ }^{\circ} 02 / 2002$ ).

Tais modificações foram incorporadas na área de Educação Física a partir das DCN de 2004 (Res. CNE/CES n. ${ }^{\circ}$ 07/2004), assegurando duas formações distintas com base em suas peculiaridades. A necessidade de fortalecer e melhorar a formação de professores fez com que novas DCN para os cursos de licenciatura fossem elaboradas. Assim, em 2015, foi promulgada a Resolução n. ${ }^{\circ} 02$ (Res. CNE/CP n. ${ }^{\circ}$ 02/2015).

Destarte, este estudo objetivou identificar os desafios apresentados na configuração dos textos das Diretrizes Curriculares Nacionais e consecutivas Resoluções que orientam a formação em Educação Física e a formação dos professores que atuam na Educação Básica, publicadas no período de 1939 a 2015, correlacionando os pontos de vistas dentro dos grupos políticos relacionados com a Educação Física brasileira.

Esses grupos foram selecionados mediante a influência e o envolvimento deles, principalmente, com as questões políticas que 
Os desafios das diretrizes curriculares nacionais para a área de educação física: uma análise... Andreia Cristina Metzner • Alexandre Janotta Drigo

permeiam a área de Educação Física. Assim, temos um grupo contrário à regulamentação da profissão e à criação do bacharelado, um grupo formado a partir do sistema de regulamentação profissional que emerge como força política, um grupo representado por gestores de cursos que têm atribuições políticas, gerenciais e acadêmicas em instituições de grande renome e, por fim, um grupo de pesquisadores que tem como foco o estudo e a pesquisa na área de formação profissional e de professores. Esses grupos, de acordo com Drigo et al. (2020), tensionam a área de Educação Física.

No presente estudo, realizamos um recorte dos documentos curriculares publicados entre 1939 e 2015. Ou seja, partimos do Decreto-Lei n. ${ }^{\circ} 1212$ de 17 de abril de 1939 que cria a Escola Nacional de Educação Física e Desportos, bem como estabelece as diretrizes para a formação profissional em Educação Física, findando no ano de 2015 com a promulgação da Resolução n. ${ }^{\circ}$ 02, que define as DCN para a formação inicial em nível superior (cursos de licenciatura, cursos de formação pedagógica para graduados e cursos de segunda licenciatura) e para a formação continuada.

\section{Percurso metodológico}

\section{Caracterização do estudo}

Este estudo tem como base os pressupostos da abordagem qualitativa (MINAYO, 2009) e o método utilizado foi a pesquisa descritiva-analítica. O método descritivo tem como características "observar, registrar, analisar, descrever e correlacionar fatos ou fenômenos sem manipulá-los, procurando descobrir com precisão a frequência em que um fenômeno ocorre e sua relação com outros fatores" (MATTOS; ROSSETO JÚNIOR; BLECHER, 2004, p. 15). Já as pesquisas analíticas contemplam o estudo aprofundado das informações coletadas com o intuito de explicar e contextualizar um fenômeno (THOMAS; NELSON, 1996). Assim, a presente pes- 
Os desafios das diretrizes curriculares nacionais para a área de educação física: uma análise... Andreia Cristina Metzner • Alexandre Janotta Drigo

quisa buscou realizar, a partir da conexão entre os dois métodos, um estudo detalhado envolvendo coleta, análise e interpretação de dados.

\section{Participantes}

Os participantes nesta pesquisa foram selecionados de forma intencional, ou seja, optamos por uma amostra não probabilística (GIL, 2008). Assim, a escolha dos sujeitos da pesquisa realizou-se por meio do interesse na opinião específica de pessoas que fazem parte de quatro grupos relacionados à Educação Física e que têm representatividade social, política e científica nesse setor.

Nesse sentido, fizeram parte da amostra os profissionais de Educação Física que ocupam cargos em Entidade Científica com atuação nacional, nas Coordenações de Cursos de Licenciatura em Educação Física de Instituições Públicas (uma Federal e três Estaduais), no Sistema de Regulamentação Profissional, e os Pesquisadores que estudam formação profissional em Educação Física.

É importante ressaltar que os representantes da Entidade Científica pesquisada, embora não seja a totalidade desse grupo, foram escolhidos porque eles apresentam uma posição contrária à regulamentação da profissão. Já as universidades públicas tiveram um papel importante na elaboração de documentos com reflexões acerca das DCN para os cursos de Licenciatura em Educação Física. Os demais participantes selecionados são ícones historicamente reconhecidos na Educação Física, responsáveis tanto pela regulamentação da profissão como pela sistematização dos conhecimentos e saberes da área.

Participaram do estudo 20 sujeitos, sendo cinco representantes de cada um dos grupos mencionados anteriormente, conforme o quadro abaixo: 
Os desafios das diretrizes curriculares nacionais para a área de educação física: uma análise... Andreia Cristina Metzner • Alexandre Janotta Drigo

\section{Quadro 1: Participantes da Pesquisa}

\begin{tabular}{|c|c|c|}
\hline GRUPOS & PARTICIPANTES & SIGLA ADOTADA \\
\hline \multirow[t]{5}{*}{ GRUPO A - Entidade Científica com } & 1 & A1 \\
\hline & 2 & A2 \\
\hline & 3 & A3 \\
\hline & 4 & A4 \\
\hline & 5 & A5 \\
\hline GRUPO B - Coordenação de Curso de & 6 & B1 \\
\hline \multirow[t]{4}{*}{ Licenciatura em Educação Física } & 7 & B2 \\
\hline & 8 & B3 \\
\hline & 9 & B4 \\
\hline & 10 & B5 \\
\hline GRUPO C - Sistema de Regulamentação & 11 & C1 \\
\hline \multirow[t]{4}{*}{ Profissional } & 12 & C2 \\
\hline & 13 & C3 \\
\hline & 14 & C4 \\
\hline & 15 & C5 \\
\hline GRUPO D - Pesquisadores que estudam & 16 & D1 \\
\hline formação profissional em & 17 & D2 \\
\hline \multirow[t]{3}{*}{ Educação Física } & 18 & D3 \\
\hline & 19 & D4 \\
\hline & 20 & D5 \\
\hline
\end{tabular}

Fonte: Elaboração Própria

\section{Instrumentos de coleta e análise de dados}

O Projeto foi submetido ao Comitê de Ética e Pesquisa e após a sua aprovação (Parecer n. ${ }^{\circ}$ 1.658.702), iniciamos os procedimentos de coleta de dados.

Os instrumentos de coleta de dados dizem respeito às "técnicas empregadas, pelo pesquisador, para coletar, medir e/ou ava- 
Os desafios das diretrizes curriculares nacionais para a área de educação física: uma análise... Andreia Cristina Metzner • Alexandre Janotta Drigo

liar os dados buscados diretamente em suas fontes ou de maneira empírica" (MATTOS; ROSSETO JÚNIOR; BLECHER, 2004, p. 90). Para a realização deste estudo, a técnica empregada foi a entrevista semiestruturada.

A coletada de dados ocorreu ao longo do ano de 2017. A questão norteadora do presente estudo foi a seguinte: Como você vê a evolução das Diretrizes Curriculares Nacionais para a formação dos professores de Educação Física?

Por fim, no tratamento dos dados, optamos pelo procedimento denominado análise de conteúdo temática. A análise temática, proposta por Minayo (1993), tem como foco a identificação de temas relevantes num corpo de informações.

\section{Resultados e discussão}

Os resultados mostraram que, na perspectiva geral dos participantes dos grupos B, C e D (Coordenação de Curso de Licenciatura em Educação Física; Sistema de Regulamentação Profissional; Pesquisadores que estudam formação profissional em Educação Física), houve avanços nos textos das Diretrizes ao longo da história. Entre as justificativas, encontramos: uma preocupação maior com a dimensão pedagógica e com a inclusão de temas emergentes no currículo dos cursos; fortalecimento da identidade do professor; autonomia das instituições de Ensino Superior; flexibilização curricular; aprofundamento de conteúdos específicos para a formação de professores; definição do perfil do licenciado e respeito à especificidade do curso.

No caso da Educação Física, os entrevistados acreditam que os modelos propostos antes da década de 1980 foram superados a partir das DCN de 1987 (Res. CFE n. ${ }^{\circ}$ 03/1987) ao estabelecer duas formações distintas (bacharelado e licenciatura), destacando esse documento como um fator que representa uma mudança importante no rumo dos acontecimentos dentro dessa área. 
Os desafios das diretrizes curriculares nacionais para a área de educação física: uma análise... Andreia Cristina Metzner • Alexandre Janotta Drigo

Já nas falas da maioria dos participantes do grupo A (Entidade Científica com atuação nacional), notamos que eles acreditam que não houve evolução ou que ainda não é possível realizar essa afirmação visto que não existem pesquisas em grande escala que afiram e evidenciam dados válidos sobre essa questão. Apenas um entrevistado desse grupo citou que as DCN apresentam algumas iniciativas interessantes como, por exemplo, o aumento na carga horária dos cursos que impactou, especialmente, as instituições particulares.

Através da análise das entrevistas, pode-se também evidenciar que os primeiros indícios de preocupação em reestruturar os cursos de formação de professores ocorreram em 1939, conforme relata o participante D4:

Podemos considerar o ano de 1939 como um marco quando você tem a primeira Diretriz de formação na Educação Física, e dentro dessa Diretriz você tem um indicativo de formação de professor.

(D4, entrevista, 12 dez. 2017). A partir do Decreto-Lei n. ${ }^{\circ}$ 1212 de 1939 foi criada a Escola Nacional de Educação Física e Desportos, assim como foram estabelecidas as diretrizes para a formação profissional nos diversos cursos oferecidos nessa instituição de ensino: a) curso superior de Educação Física; b) curso normal de Educação Física; c) curso de técnica desportiva; d) curso de treinamento e massagem; e) curso de Medicina da Educação Física e dos Desportos. Esses cursos eram concluídos em um ano, com exceção do curso superior que era realizado em dois anos. Nesse contexto, essa instituição trouxe "a primeira experiência em nível nacional de um currículo de formação na área" (FIGUEIRÊDO PRIMO, 2009, p. 76).

No entanto, a reestruturação na área de formação de professores se efetivou somente na Resolução CFE n. ${ }^{\circ} 69$ de 1969. Esse documento restringiu as formações em Educação Física em apenas duas áreas (Licenciatura e Técnico Desportivo), além disso, reduziu as matérias básicas de fundamentação científica e incor- 
Os desafios das diretrizes curriculares nacionais para a área de educação física: uma análise... Andreia Cristina Metzner • Alexandre Janotta Drigo

porou 1.800 horas de matérias pedagógicas. Esse fato mostra que nessa legislação há um destaque para a formação de professores. Figueirêdo Primo (2009, p. 78) coaduna com essa ideia ao afirmar que

esta proposta pode ser interpretada como um avanço no que diz respeito ao currículo prescrito, na medida em que passou a reconhecer a necessidade de um conhecimento mínimo de área específico para o exercício profissional.

O final da década de 1970 e os anos 1980 foram marcados por diversos diálogos e debates em busca da construção de uma identidade para o curso de Educação Física, conforme descreve Tojal (1995):

De agosto de 1978 a março de 1987 foram realizados encontros e seminários em diversos Estados da União, reunindo Professores de Educação Física; Técnicos-Desportivos, Médicos e Acadêmicos, para discutirem as reformas necessárias no Currículo dos Cursos de Graduação em Educação Física (TOJAL, 1995, p. 73).

Essas discussões resultaram na promulgação da Resolução CFE n. 03 de 1987 que determinou a carga horária mínima de 2.880 horas, reconheceu o curso de bacharelado, proporcionou flexibilidade e autonomia às universidades, alterou o formato do currículo substituindo as disciplinas/matérias por campos de conhecimentos (BRASIL, 1987).

Destarte, a implementação dessa legislação proporcionou significativas mudanças nos cursos de formação profissional em Educação Física, principalmente, ao dar autonomia às instituições de Ensino Superior para compor a sua grade curricular de acordo com o perfil profissional desejado (FIGUEIRÊDO PRIMO, 2009), ao reconhecer o curso de bacharelado e delimitar o papel mercadológico dessa área (FARIA JÚNIOR, 2001), ao extinguir a estruturação do currículo em forma de disciplinas/matérias e substituí-las por 
Os desafios das diretrizes curriculares nacionais para a área de educação física: uma análise... Andreia Cristina Metzner • Alexandre Janotta Drigo

duas grandes áreas de conhecimento - conhecimentos de cunho humanístico e conhecimentos de cunho técnico (OLIVEIRA, 2006).

Esses apontamentos foram identificados nas falas de dois entrevistados. O participante $\mathrm{C} 5$ disse que:

[...] teve uma evolução das Diretrizes anteriores para a 87. [...] ela equiparava a licenciatura com o bacharel, eram quatro anos de curso para os dois, aí havia uma preocupação muito grande da Educação Física em formar pessoas com o perfil profissiográfico diferente para trabalhar na escola atendendo toda a história da Educação Física e a legislação, e um profissional que trabalhasse fora da escola (C5, entrevista, 13 abr. 2017).

O Participante D3, por sua vez, afirmou que:

[...] ela reflete movimentos no campo tanto do contexto acadêmico como de formação do mercado de trabalho, ele vê a criação do bacharelado e admite que a formação do profissional de Educação Física é multidisciplinar, tem que contemplar as Ciências Humanas, conhecimentos da área biológica, do ser humano, da sociedade, ou seja, ser humano, sociedade e conhecimento técnico (D3, entrevista, 12 abr. 2017).

Em 2002, foram instituídas as DCN para a formação de professores de Educação Básica, Resoluções CNE/CP n. ${ }^{\circ} 01$ (BRASIL, 2002a) e n. ${ }^{\circ} 02$ (BRASIL, 2002b). Esses documentos foram editados com o intuito de nortear os cursos de licenciatura, em nível superior. Para Fávaro, Nascimento e Soriano (2006, p. 201), essas Resoluções consolidaram a "necessidade de uma re-leitura do entendimento de Licenciatura de maneira geral". Além disso, na visão de Bianchini (2015), também demonstraram uma preocupação em fortalecer as relações entre teoria e prática, e entre os conhecimentos acadêmicos e a sua aplicação no contexto escolar. 
Os desafios das diretrizes curriculares nacionais para a área de educação física: uma análise... Andreia Cristina Metzner • Alexandre Janotta Drigo

Esses fatos foram externados pelos participantes B4 e C5 ao afirmarem que:

[...] a partir dos anos 2000, existe uma grande preocupação com o quesito da formação do professor e qual é a identidade desse professor, qual é o perfil, qual é a missão da educação.

(B4, entrevista, 20 nov. 2017);

[...] As Diretrizes 01 e 02 também ajudaram a definir a licenciatura, definiu claramente a licenciatura, a geografia social onde quem vai entrar na licenciatura é para ser professor.

(C5, entrevista, 13 abr. 2017).

Posteriormente, de acordo com as orientações fornecidas pelas DCN de 2002 (Res. CNE/CP n. ${ }^{\circ} 01$ e n. ${ }^{\circ}$ 02/2002), foram instituídas novas Diretrizes para os cursos de Educação Física por meio da Resolução CNE/CES n. 07 de 2004 (BRASIL, 2004). Podemos dizer que esse documento trouxe mudanças, principalmente, em relação aos objetivos e perfis profissionais almejados na formação inicial, tanto dos licenciados quanto dos bacharéis em Educação Física. Para o participante D4, "A Diretriz de 2004 vai tentar corrigir as lacunas da 03" (D4, entrevista, 12 dez. 2017). Ou seja, a partir dessa Diretriz ficou caracterizada legalmente a distinção entre os campos de atuação do graduado/bacharel e do licenciado em Educação Física.

Portanto, as Diretrizes Curriculares de 2004 (Res. CNE/CES n. ${ }^{\circ}$ 07/2004) inovaram no quesito de apontar que fossem definidos currículos próprios para a licenciatura e para o bacharelado, buscando contemplar as necessidades específicas desses dois campos de atuação profissional, conforme evidenciado nos artigos $1^{\circ}, 4^{\circ} \mathrm{e}$ $8^{\circ}$ desse documento que estabelecem orientações e unidades de conhecimentos específicas para a licenciatura em Educação Física, tendo como referência os termos definidos nas Diretrizes para a Formação de Professores da Educação Básica (BRASIL, 2004).

Ressaltamos que o termo graduação, presente na Resolução CNE/CES n. ${ }^{\circ} 07$ de 2004, pode ser entendido como homologo ao bacharelado, já que esse documento define a formação em Educação 
Os desafios das diretrizes curriculares nacionais para a área de educação física: uma análise... Andreia Cristina Metzner • Alexandre Janotta Drigo

Física para o âmbito extraescolar e estabelece orientações específicas para a licenciatura plena a partir das Resoluções propostas pelo Conselho Nacional de Educação (METZNER; CESANA; DRIGO, 2016). Entretanto, é importante destacar que essa não é uma interpretação única e, por isso, é possível encontrar na literatura outros modos de compreender esse aspecto.

Martins e Batista (2006), com base nessas premissas, definem cada uma dessas áreas:

A licenciatura deve tomar como referência, para a constituição do seu currículo, as diretrizes estruturadas no parecer CNE/CP 009/2001 e nas resoluções CNE/CP 001/2002 e 02/2002, objetivando, no desenvolvimento de seu curso, capacitar o profissional de educação física para atuar em instituições públicas ou privadas de ensino da educação básica, ou seja, na educação infantil, no ensino fundamental e no ensino médio (MARTINS; BATISTA, 2006, p. 160, grifo nosso).

A graduação, ou, como mais comumente denominamos, o bacharelado, referencia-se no parecer CNE/CP 0058/2004 e na resolução CNE/CES 007/2004 que o instituiu, perspectivando a formação do profissional de educação física e habilitando-o a atuar em diferentes campos como planejador, organizador, administrador, orientador de atividades físicas, esportivas e de recreação e lazer, em instituições públicas e privadas, atuando em academias, clubes esportivos etc., podendo ainda realizar atividades de lazer em redes hoteleiras, orientação postural em empresas, assessorias de esportes e lazer em prefeituras, e na área de saúde na orientação de atividades que visem à prevenção de doenças e à manutenção e melhoria da saúde (MARTINS; BATISTA, 2006, p. 160-161, grifo nosso).

Por fim, temos a Diretriz Curricular n. ${ }^{\circ} 02$ de 2015 (Res. CNE/ $\left.\mathrm{CP} \mathrm{n}^{\circ} 02 / 2015\right)$ que apresenta, dentre os seus diversos princípios, a valorização do profissional da educação e a unidade teoria-prática. Além disso, ampliou a carga horária dos cursos de licenciatura e estes passaram a portar, novamente, quatro anos de duração 
Os desafios das diretrizes curriculares nacionais para a área de educação física: uma análise... Andreia Cristina Metzner • Alexandre Janotta Drigo

(BRASIL, 2015). Dessa forma, conforme o relato do participante C5, "a 02 de 2015 define melhor o curso e a formação no sentido das práticas. [...] Avançou na tentativa de resgatar o status do professor" (C5, entrevista, 13 abr. 2017).

Em dezembro de 2016, a Revista Pensar a Prática produziu um Dossiê Temático sobre as Diretrizes Curriculares Nacionais e a Educação Física e nessa edição foram publicados seis artigos a respeito desse tema ${ }^{3}$. Dentre esses textos, encontramos as considerações feitas por Rodrigues et al. (2016) em relação a Resolução CNE/CP n 02/2015. Para os autores, esse documento traz de forma muito clara "a Educação Básica como espaço de atuação do egresso dos cursos de licenciatura" (Rodrigues et al., 2016, p. 715). Além disso, tem como foco a formação para a atuação na Educação Básica, visando à integralidade, terminalidade e identidade próprias para essa área.

Em outro artigo dessa mesma edição temática, Castellani Filho (2016) aponta que as DCN de 2015 poderiam trazer possíveis ganhos para a formação do licenciado em Educação Física visto que essas Diretrizes buscam a centralidade da formação vinculada à questão da educação escolar, incorporando os conhecimentos teóricos e práticos necessários para que professores possam desempenhar as suas tarefas educacionais no âmbito do ensino formal. No caso da Educação Física, "jamais em sua história a formação do licenciado se deu a partir da problemática própria à educação escolar brasileira" (CASTELLANI FILHO, 2016, p. 765).

Apesar dos entrevistados indicarem avanços e benefícios trazidos pelas DCN ao longo do tempo, eles também apresentam em seus depoimentos alguns pontos que merecem certa atenção, dentre eles: o "inchaço" dos currículos (B2, entrevista, 20 abr. 2017); perda do núcleo "duro" da formação (C1, entrevista, 04 maio 2017); dificuldades na implantação da legislação (D1, entrevista, 03 maio 2017); falta clareza na especificidade do curso e na estruturação dos currículos (D2, entrevista, 17 nov. 2017; D5, entrevista, 31

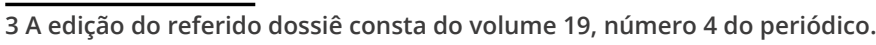


Os desafios das diretrizes curriculares nacionais para a área de educação física: uma análise... Andreia Cristina Metzner • Alexandre Janotta Drigo

ago. 2017); na prática não há alteração nos cursos (D3, entrevista, 12 abr. 2017).

Em relação a essas ressalvas, percebemos que elas estão ligadas, especialmente, à falta de clareza na especificidade do curso, estruturação da sua grade curricular e na dificuldade de implantação: "[...] Na medida em que ela dá uma abertura ela também perde naquilo que eu considero o núcleo duro da nossa formação" (C1, entrevista, 04 maio 2017);

[...] As Diretrizes precisam conseguir uma estrutura para formar profissionais para que possam atuar na condição das escolas. Nenhuma deixa claro que você tem que fazer isso na formação.

(D2, entrevista, 17 nov. 2017); e o participante D1 acrescenta que:

[...] quando chega no momento da implementação/implantação me parece que fica tudo muito solto. As Diretrizes Curriculares servem para os burocratas acharem que estão tendo um controle, um monitoramento da situação, quando na verdade aquilo que acontece na realidade é que cada um faz o que bem entende (D1, entrevista, 03 maio 2017).

Figueirêdo Primo (2009) corrobora com esses apontamentos ao dizer que, no caso da flexibilidade curricular conquistada, apesar das instituições de ensino terem ganhado autonomia, também se abriu, de certa forma, perigosas possibilidades de aproximação dos currículos dos cursos a determinadas demandas emergentes do mercado. Já as dificuldades em concretizar a efetivação das Diretrizes acontecem, de acordo com Silva (2014, p. 51), porque o contexto educacional sempre esteve marcado por "um descompasso entre a elaboração e implementação das políticas educacionais", principalmente, por haver uma separação entre os responsáveis pela estruturação das leis e os seus executores, nesse caso os gestores e professores. 
Os desafios das diretrizes curriculares nacionais para a área de educação física: uma análise... Andreia Cristina Metzner • Alexandre Janotta Drigo

Já os participantes com posicionamento contrário sobre os possíveis progressos das DCN, como apontamos anteriormente, justificaram que não houve evolução porque as estruturações das Diretrizes estão pautadas nos interesses do mercado e na organização precária do mundo do trabalho proveniente das mudanças neoliberais, conforme revela o relato do participante A1:

O que está ocorrendo é um enorme retrocesso vez que o conjunto de medidas que estão sendo adotadas nas instâncias de governo demonstram que o conservadorismo, os interesses do mercado, a lógica da super exploração do trabalho e do trabalhador estão sendo implementadas no Brasil.

(A1, entrevista, 29 out. 2017).

Taffarel e Santos Júnior (2010) afirmam que as políticas governamentais brasileiras emanadas desde a presidência de Fernando Henrique Cardoso não alteraram a hegemonia capitalista presente nas leis e, consequentemente, as DCN para os cursos de Educação Física também foram construídas nesse contexto neoliberal. E com o intuito de ressaltar esse posicionamento, os autores citam que a Resolução CNE/CES n. ${ }^{\circ} 07$ de 2004 nada mais é do que

um museu de grandes novidades, que mais confunde que esclarece e que não serve como instrumento para alavancar um processo de formação de professores de Educação Física calcado numa perspectiva emancipatória (TAFFAREL; SANTOS JÚNIOR, 2010, p. 31, grifo do autor).

A política neoliberal busca, segundo Nozaki (2004), reordenar a formação humana a partir das demandas dos dias atuais, assim, no campo da educação, as políticas educacionais são reajustadas com o intuito de formar novas competências e proporcionar a qualificação necessária para o enquadramento dos futuros trabaIhadores. $O$ autor ressalta que, em relação à Educação Física, esta tem perdido espaço no contexto escolar visto que, aos olhos do projeto dominante de formação humana, o mundo do trabalho tem como prioridade as disciplinas escolares que desenvolvem a 
Os desafios das diretrizes curriculares nacionais para a área de educação física: uma análise... Andreia Cristina Metzner • Alexandre Janotta Drigo

alfabetização, o raciocínio lógico e as inovações tecnológicas, que são as bases necessárias para dar o aporte funcional para o novo tipo de trabalhador. Nesse caso, a Educação Física, bem como as Artes, torna-se "artigo de luxo", e são colocadas em um plano secundário.

Para efetivar a lógica neoliberal de formação dos trabalhadores, diversos mecanismos legais foram produzidos e implementados. Assim, no que tange às DCN para os cursos superiores, Nozaki (2004, p. 103) afirma que o Conselho Nacional de Educação estabeleceu orientações gerais para a reformulação desses documentos tendo em vista "organizar um modelo capaz de adaptar-se às dinâmicas condições de perfil profissional exigido pela sociedade, sob o aspecto da formação polivalente e flexível".

Assim sendo, os motivos apresentados por Taffarel e Santos Júnior (2010) e Nozaki (2004) subsidiam as opiniões expostas pelos participantes A1 e A4 ao acreditarem que não houve progresso nas reformulações das DCN ao longo do tempo.

Outros apontamentos realizados pelos participantes do grupo A mostram que não existem dados representativos para firmar se as mudanças efetuadas nas DCN foram positivas ou negativas, pois essas alterações ocorreram sem uma análise prévia e sem a realização de pesquisas concretas e significativas das instituições de Ensino Superior que possuem cursos de Educação Física, por conseguinte, as modificações na legislação aconteceram "influenciadas pela força da lei e cada IES forma seus estudantes de acordo com a realidade na qual está inserida" (A5, entrevista, 24 ago. 2017). Para outro participante desse grupo,

Nós temos hoje uma lógica de alteração de uma Diretriz que não está se dando, digamos, a partir de estudos de natureza acadêmica, pesquisas sérias, portanto, que abarquem a totalidade desses cursos ou que tenham um patamar de amostragem que possa nos dizer o que vem acontecendo nesses 10 anos de funcionamento, de implantação da 07 de 2004 (A3, entrevista, 22 dez. 2017). 
Os desafios das diretrizes curriculares nacionais para a área de educação física: uma análise... Andreia Cristina Metzner • Alexandre Janotta Drigo

Castellani Filho (2016, p. 765) avaliza esses apontamentos ao afirmar que não existem

estudos que abarquem os aproximadamente 1.400 cursos superiores de $\mathrm{EF}$, de modo a darem conta da análise dos impactos das diretrizes curriculares - tanto das atuais quanto da que a antecedeu.

Nesse caso, o autor está referindo-se às Diretrizes Curriculares n. ${ }^{\circ}$ 07/2004 e n. ${ }^{\circ}$ 03/87, respectivamente. Portanto, sem indicadores para comprovar ou refutar de que maneira as reformas educacionais estão se efetivando na prática, fica difícil desenredar o seu real impacto.

Acreditamos que, apesar de não existirem estudos abrangendo a totalidade de cursos de Educação Física, temos produções científicas significativas sobre as diretrizes e propostas curriculares que nos fornecem subsídios para projetar de que forma estão se efetivando na prática. Entre essas produções, destacamos: Kunz (2003); Souza Neto (1999), Taffarel (1998, 2012), Santos Júnior (2005) e Marques e Figueiredo (2014).

As intenções dos idealizadores e elaboradores das DCN para os cursos de graduação, bem como das demais normas legais, são de melhorar a formação inicial. No entanto, na prática, nem sempre isso acontece como o esperado. Canário (2005, p. 93) corrobora com essas afirmativas ao afirmar que apesar das instituições de ensino ter que cumprir as Diretrizes Curriculares, essas reformas acabam produzindo "mudanças formais, mas, raramente, transformações profundas, duráveis e conformes com as expectativas dos reformadores".

Isso posto, sob nossa análise, os resultados expostos indicam que as DCN apresentam, em certo ponto, características embrionárias e parciais de mudanças relativamente significativas no campo da formação de professores. A busca por uma transformação efetiva nos cursos de formação inicial nos leva a reforçar a necessidade de estabelecer um diálogo permanente entre o que é de- 
Os desafios das diretrizes curriculares nacionais para a área de educação física: uma análise... Andreia Cristina Metzner • Alexandre Janotta Drigo

terminado pela legislação e o enfoque adotado pelas instituições de Ensino Superior.

\begin{abstract}
A primeira condição de uma reforma transformadora da realidade seria a de clarificar, para não confundir nem se auto-enganar, que desafios concretos coloca e com que medida pensa em alcançá-los; do contrário só servirá ao ritual da confusão de fazer com que tudo se mova para que nada mude (SACRISTÁN, 1996, p. 58).
\end{abstract}

Assim, para que as reformas educacionais e as suas implementações nas instituições de ensino caminhem na mesma direção, é preciso fortalecer ainda mais as pesquisas a respeito dos processos educativos que delineiam as atividades pedagógicas na formação dos profissionais de educação, além de lidar com resistências políticas e sociais.

Quanto às DCN para a área de Educação Física, notamos que houve um consenso parcial entre os participantes desse estudo sobre as suas conquistas obtidas ao longo dos anos e das mudanças legais, sendo que três grupos defendem a visão de que as Diretrizes trouxeram mudanças positivas nos cursos de formação profissional. Apenas um grupo entende que não houve avanços ou que esses avanços foram muito pequenos, uma vez que esses documentos foram construídos e cercados por processos de hibridação, sobretudo no âmbito da lógica neoliberal da área de Educação Física.

Dessa forma, acreditamos que as DCN reverberam os embates no campo, pois não somente essas Diretrizes como também a legislação de forma geral tornam-se objetos de disputas entre os diferentes grupos que buscam o domínio de um modelo de formação na Educação Física.

Apesar das DCN para os cursos de licenciatura buscarem inovações e currículos com novas visões, podemos perceber que na área de Educação Física os documentos não possuem uma direção 
Os desafios das diretrizes curriculares nacionais para a área de educação física: uma análise... Andreia Cristina Metzner • Alexandre Janotta Drigo

definida e, portanto, ora abrem espaço e margem para servir a determinados interesses de um grupo ora os de outro.

A título de exemplo, citamos as Resoluções n. ${ }^{\circ}$ 03/87 e n. ${ }^{\circ}$ 07/2004. A Resolução n. 03 abrange em seus currículos, na parte identificadora da área, conhecimentos de cunho social/técnico, prevalecendo a parte técnica com $80 \%$ da carga horária. Já a Resolução $n^{\circ} .07$ possui uma organização curricular pautada em dimensões cultural/técnico/pedagógico, deixando a cargo das IES definir as respectivas cargas horárias. Assim, notamos que enquanto a Resolução n. ${ }^{\circ}$ 03/87 tem uma preocupação com o desenvolvimento social e biológico, a Resolução n. ${ }^{\circ}$ 07/2004 contempla aspectos culturais e pedagógicos do movimento humano. Essas alterações e processos não lineares podem ser entendidos como uma forma de expressão dos embates e disputas que cercam os textos políticos, de demarcação da área de Educação Física, exigindo que novos critérios e procedimentos sejam utilizados na formação profissional.

Considerando esses aspectos, entendemos que as DCN para a formação de professores de Educação Física estão se diversificando e se dinamizando, porém, ainda representam disputas estabelecidas entre os grupos que almejam conquistar ou preservar o poder instituído nessa área, inculcando novas formas de pensar, ver e estruturar a formação inicial docente.

\section{Conclusão}

Os resultados encontrados indicaram que os principais desafios da formação em Educação Física estão relacionados ao fortalecimento da identidade docente sem a perda da especificidade da área. E vimos, também, que as modificações ocorridas nos textos das DCN caminharam em busca da criação de cursos de licenciatura com identidade e integralidade própria, desvinculando-se dos cursos de bacharelado. 
Os desafios das diretrizes curriculares nacionais para a área de educação física: uma análise... Andreia Cristina Metzner • Alexandre Janotta Drigo

Em relação à Educação Física, notamos que os grupos que se apresentam em disputa pelo poder e hegemonia da área veem nesses documentos legais uma forma de disseminarem as suas ideias ou regras para afirmar sua presença nesse campo. A exemplo disso, percebe-se o exposto pelo grupo A, que coloca em xeque à afirmação de se ter avanços na área a partir das DCN.

Por fim, sugerimos que novos trabalhos sejam realizados com o intuito de aprofundar o tema em questão visto que novas DCN que tratam da formação de professores e da formação em Educação Física foram promulgadas recentemente.

\section{Referências}

BIANCHINI, L. Movimento renovador na Educação Física e currículo: formação docente e consciência crítica. 2015. 264f. Dissertação (Mestrado em Educação Física) - Centro de Desportos, Universidade Federal de Santa Catarina, Florianópolis/ SC, 2015.

BORGES, C.M.F. O professor de Educação Física e a construção do saber. Campinas, SP: Papirus, 1998.

BRASIL. Conselho Nacional de Educação. Resolução CNE/CP n. ${ }^{\circ} \mathbf{2}$ de $1^{\circ}$ de julho de 2015. Define as Diretrizes Curriculares Nacionais para a formação inicial em nível superior (cursos de licenciatura, cursos de formação pedagógica para graduados e cursos de segunda licenciatura) e para a formação continuada. Brasília/DF, 2015.

BRASIL. Conselho Nacional de Educação. Resolução CNE/CES n. ${ }^{\circ} 7$ de 31 de março de 2004. Institui as Diretrizes Curriculares Nacionais para os cursos de graduação em Educação Física, em nível superior de graduação plena. Brasília/DF, 2004.

BRASIL. Conselho Nacional de Educação. Resolução CNE/CP n. ${ }^{\circ}$ 1 de 18 de fevereiro de 2002. Institui Diretrizes Curriculares Nacionais para a Formação de Professores da Educação Básica, 
Os desafios das diretrizes curriculares nacionais para a área de educação física: uma análise... Andreia Cristina Metzner • Alexandre Janotta Drigo

em nível superior, curso de licenciatura, de graduação plena. Brasília/DF, 2002a.

BRASIL. Conselho Nacional de Educação. Resolução CNE/CP n. ${ }^{\circ}$ 2 de 19 de fevereiro de 2002. Institui a duração e a carga horária dos cursos de licenciatura, de graduação plena, de formação de professores da Educação Básica em nível superior. Brasília/DF, 2002b.

BRASIL. Conselho Federal de Educação. Resolução CFE n. ${ }^{\circ} 03$ de 16 de junho de 1987. Fixa os mínimos de conteúdo e duração a serem observados nos cursos de graduação em Educação Física (Bacharelado e/ou Licenciatura Plena). Brasília/DF, 1987.

CANÁRIO, R. O que é a Escola? Um “olhar" sociológico. Porto: Porto Editora, 2005.

CASTELLANI FILHO, L. A formação sitiada - Diretrizes Curriculares de Educação Física em disputa: jogo jogado? Pensar a Prática, Goiânia, v. 19, n. 4, p. 758-773, 2016. Disponível em: https://www.revistas.ufg.br/fef/article/view/42256. Acesso em: 5 jun. 2018.

DRIGO, A. J. et al. The socio-political scene and Henry's crisis influence on the curricula of physical education undergraduate courses in Brazil. Journal of Physical Education, Maringá-PR, $v$. 31, n. 1, p. 1-13, 2020.

FARIA JÚNIOR, A. G. Reflexões sobre a Educação Física brasileira - a carta de Belo Horizonte. Revista Brasileira de Ciências do Esporte, São Paulo, v. 23, n. 1, p. 19-31, 2001.Disponível em: http://revista.cbce.org.br/index.php/RBCE/article/view/317. Acesso em: 7 abr. 2018.

FÁVARO, P. E.; NASCIMENTO, G. Y.; SORIANO, J. B. O Conteúdo da Intervenção Profissional em Educação Física: o ponto de vista de docentes de um curso de formação profissional. Movimento, Porto Alegre, v. 12, n. 2, p. 199-221, 2006. ISSN 0104-754X. DOI10.22456/1982-8918.2901. Disponível em: https://seer.ufrgs. br/Movimento/article/view/2901. Acesso em: 15 jul. 2019. 
Os desafios das diretrizes curriculares nacionais para a área de educação física: uma análise... Andreia Cristina Metzner • Alexandre Janotta Drigo

FIGUEIRÊDO PRIMO, C. P. O curso de licenciatura em Educação Física da UFBA: uma análise da formação acadêmica e do exercício profissional de seu egresso no mundo do trabalho. 2009. 253f. Tese (Doutorado em Educação) - Faculdade de Educação, Universidade Federal da Bahia, Salvador, 2009.

GIL, A. C. Métodos e técnicas de pesquisa social. 6. ed. São Paulo: Atlas, 2008.

KUNZ, E. Formação profissional em Educação Física: revisões e alienações. Motrivivência, Florianópolis-SC, ano XV, n. 20-21, p. 189-197, 2003. Disponível em: https://periodicos.ufsc.br/index. php/motrivivencia/article/view/915. Acesso em: 25mar. 2018.

MARQUES, F. B.; FIGUEIREDO, Z. C. C. Diretrizes curriculares nacionais e suas repercussões nos currículos de formação docente em Educação Física. Motrivivência, Florianópolis-SC, v. 26, n. 43, p. 30-43, 2014. Disponível em: https://periodicos.ufsc.br/ index.php/motrivivencia/article/view/2175-8042.2014v26n43p30. Acesso em: 12 out. 2017.

MARTINS, I. C.; BATISTA, J. C. F. Educação Física, formação e prática profissional. In: DE MARCO, Ademir (org.). Educação física: cultura e sociedade. Campinas, SP: Papirus, 2006. p. 157-170. MATTOS, M. G.; ROSSETO JÚNIOR, A. J.; BLECHER, S. Teoria e Prática da Metodologia da Pesquisa em Educação Física: construindo sua monografia, artigo e projeto de ação. São Paulo: Phorte Editora, 2004.

METZNER, A. C.; CESANA, J.; DRIGO, A. J. Diretrizes Curriculares Nacionais e a Educação Física: levantamento das produções acadêmicas e científicas dos últimos 10 anos. Pensar a Prática, Goiânia, v. 19, n. 4, p. 747-757, 2016. Disponível em: https://www. revistas.ufg.br/fef/article/view/42252/pdf. Acesso em: 20 ago. 2021.

MINAYO, M. C. S. O desafio da pesquisa social. In: MINAYO, M. C. S (org); DESLANDES, S. F.; GOMES, R. Pesquisa Social: teoria, método e criatividade. Petrópolis, RJ: Vozes, $28^{\text {a }}$ ed., 2009. p. 09-29. 
Os desafios das diretrizes curriculares nacionais para a área de educação física: uma análise... Andreia Cristina Metzner • Alexandre Janotta Drigo

MINAYO, M. C. S. O desafio do conhecimento: pesquisa qualitativa em saúde. São Paulo: Hucitec, 1993.

NOZAKI, H. T. Educação Física e reordenamento no mundo do trabalho: Mediações da regulamentação da profissão. 2004. 383f. Tese (Doutorado em Educação) - Faculdade de Educação, Universidade Federal Fluminense, Niterói, 2004.

OLIVEIRA, A. B. A formação profissional no campo da Educação Física: legislação, limites e possibilidades. In: SOUZA NETO, S.; HUNGER, D. (org.). Formação profissional em Educação Física: estudos e pesquisas. Rio Claro: Biblioética, 2006. p. 17-32.

RODRIGUES, A. T. et al. Análise da minuta de projeto de resolução de Diretrizes Curriculares Nacionais para o curso de Educação Física e a questão da formação para a docência na educação básica. Pensar a Prática, Goiânia, v. 19, n. 4, p. 711-720, 2016. Disponível em: https://www.revistas.ufg.br/fef/article/view/42160. Acesso em: 19 ago. 2021.

SANTOS JUNIOR, C.L. A formação de professores em Educação Física: a mediação dos parâmetros teóricos metodológicos. 2005. 194f. Tese (Doutorado em Educação) - Faculdade de Educação, Universidade Federal da Bahia, Salvador, 2005.

SILVA, S. P. O processo de implementação das políticas educacionais e repercussões nas formas de gestão da escola e no processo de ensino-aprendizagem: o pacto pela educação em Goiás. 2014. 249f. Tese (Doutorado em Educação) - Faculdade de Educação, Pontifícia Universidade Católica de Goiás, Goiânia, 2014.

SOUZA NETO, S. A Educação Física na Universidade: licenciatura e bacharelado - as propostas de formação profissional e suas implicações teórico-práticas. 1999. 336f. Tese (Doutorado em Educação) - Instituto de Educação, Universidade de São Paulo, São Paulo, 1999.

TAFFAREL, C. N. Z. Formação de professores de Educação Física: diretrizes para a formação unificada. Revista Kinesis, Santa Maria - RS, v. 30, n. 1, p. 95-133, 2012. 
Os desafios das diretrizes curriculares nacionais para a área de educação física: uma análise... Andreia Cristina Metzner • Alexandre Janotta Drigo

TAFFAREL, C. N. Z.; SANTOS JÚNIOR, C. L. Formação humana e formação de professores de Educação Física: para além da falsa dicotomia licenciatura $\mathrm{x}$ bacharelado. In: TERRA, D. V.; SOUZA JÚNIOR, M. (org). Formação em Educação Física \& Ciências do Esporte: políticas e cotidiano. São Paulo: Aderaldo \& Rothschild: Goiânia, GO: CBCE, 2010. p. 13-47.

TAFFAREL, C. N. Z. A formação profissional e as diretrizes curriculares do programa nacional de graduação: o assalto às consciências e o amoldamento subjetivo. Revista da Educação Física/UEM, Maringá-PR, v. 9, n. 1, p. 13-23, 1998. Disponível em: http://www.periodicos.uem.br/ojs/index.php/RevEducFis/article/ view/3823. Acesso em: 10out. 2018

THOMAS, J. R.; NELSON, J. K. Research methods in physical activity. 3.ed. Champaign: Human Kinetics, 1996.

TOJAL, J. B. A. G. Currículo de graduação em Educação Física: a busca de um modelo. Campinas: Editora da UNICAMP, 1995.

\section{Publisher}

Universidade Federal de Goiás. Faculdade de Educação Física e Dança. Publicação no Portal de Periódicos UFG. As ideias expressadas neste artigo são de responsabilidade de seus autores, não representando, necessariamente, a opinião dos editores ou da universidade. 